\title{
Validity of a simplified screening instrument for assessing overweight children in a dental setting: a cross sectional study
}

\author{
Amir Azarpazhooh ${ }^{1,2,3,4^{*}}$ (D) Anoushe Sekhavat ${ }^{1}$ and Michael J. Sigal ${ }^{1,2}$
}

\begin{abstract}
Background: Obesity, with its rising prevalence among Canadians and its estimated cost of $\$ 2$ billion annually in Canada, is no longer considered a cosmetic issue, but a major health issue that imposes a great burden on the healthcare system and economy. This cross sectional study aims to evaluate the feasibility of identifying the weight status of 6 to 11 year-old children in a university dental clinic using a simplified overweight screening instrument.

Methods: One hundred sixty eight healthy children were enrolled. Weight and height were measured and overweight/obesity status was assessed using two techniques: 1) the 2007 World Health Organization Body Mass Index (BMI)-for-age reference Tables, 2) simplified overweight screening instrument without BMI calculation. Measures of overall, positive, and negative percent agreement between the two approaches were computed.

Results: The children's average weight, height, BMI and BMI z-score were respectively $32.6 \pm 9.5 \mathrm{~kg}, 133.8 \pm 10.7 \mathrm{~cm}$, $17.8 \pm 3.2$, and $0.4 \pm 1.0$. The overall, positive, and negative percent agreement between the two screening approaches were respectively, 89\%, 100\%, and $83 \%$.

Conclusion: This study demonstrated the feasibility and parental acceptance of weight, height and BMI measurement in a dental setting and evidence that supports the validity of a new simplified approach to assess children's weight status without having to compute BMI.
\end{abstract}

Trial registration: NCT02637752. Registered 18 December 2015.

Keywords: Childhood obesity, Child growth, Weight, BMI (Body mass Index)

\section{Background}

The global prevalence of childhood obesity has increased at an alarming rate. In 2014, an estimated 41 million children under 5 years of age were affected by overweight or obesity, of which, almost three quarters are living in developing countries [1]. Hence, obesity is no longer considered a cosmetic issue, but one of the most serious public health challenges of the $21^{\text {st }}$ century [2], imposing a great burden on the health care system and

\footnotetext{
* Correspondence: amir.azarpazhooh@dentistry.utoronto.ca

${ }^{1}$ Faculty of Dentistry, University of Toronto, 710F-481 University Ave, Toronto, ON M5G 2P1, Canada

2Department of Dentistry, Mount Sinai Hospital, Toronto, Canada

Full list of author information is available at the end of the article
}

economy [3]. Therefore, screening children and identifying their overweight and obese status is important [4] as it leads to assessment of the associated comorbidities that occur at an earlier age and progress into adulthood [5]. For example, both Canadian and U.S. clinical practice guidelines recommend that clinicians screen children at age six and older for overweight/obesity [3, 6, 7], and that for such children, weight-related diet and exercise counselling, provided by a multidisciplinary team, should be increased [6, 8].

The most common and practical method to assess obesity in children and adolescents is the Body Mass Index (BMI), the ratio of weight in kilograms to the square of height in meters $[9,10]$. Obesity and overweight are defined through BMI-for age percentile 
plotting, with BMI from $85^{\text {th }}$ to the $94^{\text {th }}$ percentile considered overweight and BMI at or above $95^{\text {th }}$ percentile considered obese for a specific age and gender [11]. As simple as it sounds, the BMI-for age plotting is only used by half of the U.S. pediatricians and family physicians $[12,13]$. Additional undertaking and 'the cumbersome task' of computing and assessing BMI from height and weight measurements in primary care settings have also been reported as a barrier to the BMI uptake [14-16]

Another group of health care providers with the potential to screen for childhood obesity is dentists. Given 1) the higher frequency of dental visits compared to medical visits (twice a year vs. once a year, especially during childhood) [12], and 2) the routine measurement of the children's weight and height to calculate safe dosages of local anesthesia for most conscious sedation procedures or dental rehabilitation under general anesthesia, dentists, specifically pediatric dentists, have the potential to identify, assess and refer patients to appropriate resources [14]. Yet, only less than $5 \%$ of U.S. pediatric and general dentists offer a form of obesity-related services [14], because mostly they lack training and knowledge for BMI computation and interpretation and guidelines [14, 17].

Recently, a simplified overweight screening instrument was developed based on data derived from the WHO 2007 Growth Reference that would use only the child's height and weight measurements without any additional computation. This simplified screening instrument was based on age- and gender-specific +1 standard deviation $\mathrm{z}$-scores for the BMI, calculated for the various height percentiles at 6 -month age intervals (from 5 to 19 years of age), and resulted in two simple tables, one for girls and one for boys that describe overweight screening values for height measurements for all 11 percentiles as described in the 2007 WHO Reference data [18]. With the availability of this simplified approach, our study aims to evaluate the feasibility of identifying the weight status of 6 to 11 year-old children in a university dental clinic setting using either the 2007 WHO BMI-for-age tables or a simplified overweight screening instrument.

\section{Methods}

The cross sectional study refers to the baseline data of our recent randomized controlled clinical trial [18], conducted at the University of Toronto, Faculty of Dentistry from September 2011 to April 2014 (Trial Registration No. NCT02637752). The research protocol and its written informed consent were approved by the Research Ethics Board of the University of Toronto (Protocol No. 28052). The methodology was described in detail previously [19].

In brief, the study population consisted of 168 healthy children (6 to 11 years of age) who attended the undergraduate pediatric dentistry clinic for their routine dental care at the University of Toronto's Faculty of Dentistry. Upon enrolment at the initial dental visit, the children were assigned to dental students in the undergraduate or graduate pediatric clinic for their required clinical care. The caregivers completed a questionnaire about their sociodemographic characteristics, water and soft drink consumption, school nutrition policy, sedentary and physical activities and video screen time. The questionnaire was adapted mostly from the Canadian Health Measurement Survey [20] as well as other validated Canadian sources $[21,22]$. During this time, the research investigator, not involved in the children's clinical care, measured the children's weight and height. For the weight measurement, an accurate and calibrated electronic scale (Model 500KL, Health O meter ${ }^{\circ}$, USA) was used to weigh the participants [23]. The weight was measured to the nearest $0.1 \mathrm{~kg}$ with the child wearing lightweight outer clothing and standing unassisted without shoes on the center of the scale. After repositioning, the measurement was repeated. The two measurements had to agree within $0.1 \mathrm{~kg}$; otherwise, the child's weight was measured for a third time and the average of the two closest measures were then recorded [24]. For the height measurement, the child was asked to remove hair ornaments, buns, braids, etc. and stand against a calibrated stadiometer without shoes, heels together, legs straight, arms at their sides and shoulders relaxed. The horizontal headpiece of the stadiometer was brought in contact with the top part of the head. The child was instructed to look forward and inhale deeply without raising the heels off the footplate of the stadiometer. The stadiometer was read to the nearest $0.1 \mathrm{~cm}$ with the eyes of the individual taking the measurement parallel with the headpiece. The children's overweight/obesity status were then assessed using two techniques:

1) With BMI calculation: After a child's height and weight were measured, BMI was computed as weight in $\mathrm{kg} /$ (height in centimeters) ${ }^{2}$. The WHO BMI-for-age reference tables were consulted according to the gender of the individual. Then the child's age was used to determine the tabular row recommended by WHO BMI-for-age reference tables. Any computed BMI value exceeding the \pm 1 SD BMI Zscores in the screening tabular row of the table was identified as overweight [24].

2) Without BMI calculation: Overweight status was also determined using a simplified screening instrument without any computation of BMI. This instrument, available from http://dx.doi.org/10.1038/ oby.2011.159, [18] consists of two tables, one for girls (Additional file 1: Table S1) and one for boys (Additional file 1: Table S2). To ascertain the weight 
screening unit grid, the child's age was selected in the tabular row(s) followed by the height for the tabular column(s). A child was identified as overweight if his/her weight exceeded the screening unit grid. An example is shown in Fig. 1.

\section{Statistical methods}

Assuming a prevalence of unhealthy weight of $30 \%$ in the recruited sample, and using the goodness of fit tables [25], (with Kappa null value of 0.40, at two-tailed test null value $=0.40$ ) the required sample size of $n=85$ would satisfy a power of $80 \%$. The sample size was increased to 168 to satisfy the primary outcome of the larger randomized clinical trial as outlined previously [18]. Data were managed and analyzed using SAS 9.2 software (SAS Institute Inc., Cary, NC, USA). Descriptive analyses were performed using Chi-square test or student $t$-test as indicated. A $2 \times 2$ table of results comparing the two approaches for assessing overweight/obesity status were constructed and measures of overall, and positive and negative percent agreement were computed [26, 27]. Statistical tests were two-tailed and interpreted at the $5 \%$ significant level.

\section{Results}

A total of 168 subjects (mean age 107.6 \pm 18.2 months, $52.4 \%$ boys) were enrolled in this study. Many of them [Table 1] were either South Asian or Caucasian, were born in developed countries (mainly Canada), and spoke English/French. More than half of their caregivers had a university degree, worked regular daytime schedule shifts, and were low income family (receiving an annual income of $\leq 40,000$ Canadian dollars from wages and salaries). Moreover, a majority of caregivers had not received any previous nutrition/physical counselling. However, they were aware of the school nutrition policy on nutrition standards for food and beverages. A majority of caregivers provided food for their child to take to school or allowed their child to buy nutritious food at school.

Table 2 shows the height and weight measurement of the children based on their age (6-8 years and 9-11 years) and gender subgroups. The children had an average weight of $32.6 \pm 9.5 \mathrm{~kg}$ and an average height of $133.8 \pm 10.7 \mathrm{~cm}$. Their mean BMI and BMI z-score were respectively $17.8 \pm 3.2$ and $0.4 \pm 1.0$. No significant differences were noted among the participants stratified based on gender and age $(P>0.05)$.

Table 3 shows the weight status comparison by using WHO's 2007 BMI-for-age tables vs. the simplified overweight screening instrument. Using the simplified screening tables, an overall percent agreement of $89 \%$ was achieved between the two methods for detecting weight status. In particular, using the WHO 2007 BMI tables $64.9 \%$ of children had a healthy weight status, and $54.1 \%$ were identified as healthy by the simplified

\begin{tabular}{|c|c|c|c|c|c|c|c|c|c|c|c|c|c|}
\hline \multirow[t]{6}{*}{$\mathbf{a}$} & Month & $L$ & $M$ & $S$ & $\overline{\text { SD4neg }}$ & SD3neg & $\overline{\text { SD2neg }}$ & SD1neg & SD0 & $\overline{\text { SD1 }}$ & $\overline{\mathrm{SD} 2}$ & $\overline{\mathrm{SD} 3}$ & $\overline{S D 4}$ \\
\hline & 120 & -1.4864 & 16.6133 & 0.12307 & 11.285 & 12.378 & 13.47 & 14.838 & 16.613 & 19.032 & 22.57 & 28.378 & 34.185 \\
\hline & 121 & -1.4859 & 16.6612 & 0.12346 & 11.307 & 12.404 & 13.501 & 14.876 & 16.661 & 19.096 & 22.663 & 28.531 & 34.399 \\
\hline & 122 & -1.4851 & 16.71 & 0.12384 & 11.328 & 12.43 & 13.533 & 14.914 & 16.71 & 19.161 & 22.755 & 28.683 & 34.61 \\
\hline & 123 & -1.4839 & 16.7595 & 0.12422 & 11.35 & 12.458 & 13.565 & 14.954 & 16.76 & 19.226 & 22.849 & 28.834 & 34.82 \\
\hline & 124 & -1.4825 & 16.81 & 0.1246 & 11.373 & 12.485 & 13.598 & 14.994 & 16.81 & 19.293 & 22.943 & 28.987 & 35.031 \\
\hline
\end{tabular}

b

\begin{tabular}{|c|c|c|c|c|c|c|c|c|c|c|c|c|c|}
\hline \multirow{3}{*}{$\begin{array}{l}\text { Age } \\
\text { (years) }\end{array}$} & \multirow[t]{3}{*}{ BMI* } & & \multicolumn{11}{|c|}{ Height percentiles $(\mathrm{cm}) /$ screening weight (kg: bold numbers) } \\
\hline & & & \multirow[t]{2}{*}{$1 \% \mathrm{Ht}$} & \multirow{2}{*}{$3 \% \mathrm{Ht}$} & \multirow{2}{*}{$5 \% \mathrm{Ht}$} & \multirow{2}{*}{$\begin{array}{l}15 \% \\
\mathrm{Ht}\end{array}$} & \multirow{2}{*}{$\begin{array}{l}25 \% \\
\mathrm{Ht}\end{array}$} & \multirow{2}{*}{$\begin{array}{l}50 \% \\
\mathrm{Ht}\end{array}$} & \multirow{2}{*}{$\begin{array}{l}75 \% \\
\mathrm{Ht}\end{array}$} & \multirow{2}{*}{$\begin{array}{l}85 \% \\
\mathrm{Ht}\end{array}$} & \multirow{2}{*}{$\begin{array}{l}95 \% \\
\mathrm{Ht} \\
\end{array}$} & \multirow{2}{*}{$\begin{array}{l}97 \% \\
\mathrm{Ht} \\
\end{array}$} & \multirow{2}{*}{$\begin{array}{l}99 \% \\
\mathrm{Ht} \\
\end{array}$} \\
\hline & & & & & & & & & & & & & \\
\hline \multirow[t]{2}{*}{9.5} & 18.2 & Height $(\mathrm{cm})$ & 120.8 & 123.5 & 125 & 128.8 & 131 & 135.2 & 139.4 & 141.6 & 145.4 & 146.8 & 149.6 \\
\hline & & Weight (kg) & 26.5 & 27.7 & 28.4 & 30.1 & 31.2 & 33.2 & 35.3 & 36.5 & 38.4 & 39.2 & 40.7 \\
\hline \multirow[t]{2}{*}{10} & 18.5 & Height $(\mathrm{cm})$ & 123 & 125.8 & 127.3 & 131.2 & 133.5 & 137.8 & 142.1 & 144.4 & 148.3 & 149.8 & 152.6 \\
\hline & & Weight (kg) & 27.9 & 29.2 & 30 & 31.8 & 32.9 & 35.1 & 37.3 & 38.5 & 40.6 & 41.5 & 43 \\
\hline \multirow[t]{2}{*}{10.5} & 18.8 & Height (cm) & 125.2 & 128.1 & 129.6 & 133.6 & 136 & 140.4 & 144.8 & 147.2 & 151.2 & 152.7 & 155.6 \\
\hline & & Weight (kg) & 29.5 & 30.9 & 31.6 & 33.6 & 34.8 & 37.1 & 39.4 & 40.8 & 43 & 43.9 & 45.6 \\
\hline 11 & 19.2 & Height $(\mathrm{cm})$ & 127.5 & 130.5 & 132 & 136.1 & 138.6 & 143.1 & 147.7 & 150.1 & 154.2 & 155.8 & 158.8 \\
\hline
\end{tabular}

Fig. 1 Example of assessing obesity status for a 10 years 2 month old boy, (Height:146 cm; Weight: $38 \mathrm{~kg}$ ) with or without BMI calculation. a) Assessing obesity using WHO 2007 reference tables with BMI calculation. b) Assessing obesity using the simplified screening tool without BMI calculation. a) In the age row of 122 months, the BMI value for being overweight should be more than +1SD Z-score (19.16). This boy's computed BMI (38 kg/1.462 $\mathrm{m}=17.8)$ is less than his screening unit grid of 19.161 and hence, he is not overweight. $\mathbf{b})$ The age of this boy is between 10 and 10.5 years rows. In the row 10 years, the height is between $144.4 \mathrm{~cm}$ and $148.3 \mathrm{~cm}$ and in the row 10.5 years, his height is between $144.8 \mathrm{~cm}$ and $147.2 \mathrm{~cm}$. The screening weight grids for these heights are, respectively, 38.5, 40.6, 39.4, $40.8 \mathrm{~kg}$. The boy's weight ( $38 \mathrm{~kg}$ ) is below his screening unit grids and hence, he is not overweight. If his weight was $38.7 \mathrm{~kg}$, he would be placed within the screening unit grids and hence, he would have been considered overweight. In contrary, as per the 2007 WHO table, his computed BMI $\left(37.8 \mathrm{~kg} / 1.462^{2} \mathrm{~m}=18.15\right)$ is still below his screening unit grid of 19.161 and hence, he would have been considered not overweight 
Table 1 Descriptive characteristics of the study participants

\begin{tabular}{|c|c|c|}
\hline & Variables & Total \\
\hline \multirow[t]{18}{*}{ Children } & Female (\%) & 47.6 \\
\hline & Age in months (mean $\pm S D$ ) & $107.6 \pm 18.2$ \\
\hline & Racial or cultural groups (\%) & \\
\hline & South Asian & 22.6 \\
\hline & White & 21.4 \\
\hline & Black & 19.2 \\
\hline & Latin American & 8.9 \\
\hline & Southeast Asian & 7.7 \\
\hline & Asian & 6.5 \\
\hline & Arab & 6 \\
\hline & West Asian & 4.2 \\
\hline & Mixed & 1.8 \\
\hline & Native & 0.6 \\
\hline & Guyana & 0.6 \\
\hline & Missing & 0.6 \\
\hline & Not aboriginal (\%) & 98.2 \\
\hline & Born in a developed country (\%) & 74.4 \\
\hline & Speaking English/French (\%) & 88.1 \\
\hline \multirow[t]{25}{*}{ Caregivers } & Highest degree of education (\%) & \\
\hline & University degree & 54.8 \\
\hline & No university degree or diploma & 16.7 \\
\hline & Trade certificate or diploma & 13.1 \\
\hline & No post-secondary degree, diploma & 12.5 \\
\hline & Missing & 3 \\
\hline & Hours at work (\%) & \\
\hline & Regular day, evening, or night time & 59.5 \\
\hline & Rotating shift & 15.5 \\
\hline & Not working & 19.6 \\
\hline & Missing & 5.4 \\
\hline & Annual income $\leq 40000(\%)$ & 64.3 \\
\hline & Source of income (\%) & \\
\hline & Wages and salaries & 50 \\
\hline & Self-employment & 22 \\
\hline & Employment insurance & 3.6 \\
\hline & Canada pension plan & 1.2 \\
\hline & Child tax benefit & 5.4 \\
\hline & Welfare & 8.9 \\
\hline & Missing & 8.9 \\
\hline & Nutrition knowledge (\%) & \\
\hline & No previous nutrition counselling & 90.5 \\
\hline & Aware of Ontario school nutrition policy & 61.3 \\
\hline & Provided food for school & 95.8 \\
\hline & $\begin{array}{l}\text { Allowed children to buy food at school- } \\
\text { knowing the choices there are nutritious }\end{array}$ & 60.1 \\
\hline
\end{tabular}

overweight screening instrument (hence; a negative percent agreement of $83 \%$ ). The simplified overweight screening instrument had a positive percent agreement of $100 \%$ with the WHO's 2007 BMI-for-age tables in detecting overweight children.

\section{Discussion}

Childhood obesity is a much bigger concern than its obvious impact on physical health. Obese children have a lower quality of life and impaired social functioning [28], and are at an increased risk of many conditions including: type 2 diabetes, hypertension, dyslipidemia, elevated cholesterol, coronary artery disease, obstructive sleep apnea, stroke, fatty liver disease, osteoarthritis, orthopedic problems and certain forms of cancer $[3,29]$. The objective of this study was to identify the weight status of children from 6 to 11 years old in a dental setting and to evaluate the agreement between the WHO BMI-for-age tables and the simplified screening instrument tables, which were developed based on height and weight measurements and are derived from the 2007 WHO reference tables [18].

The BMI is the best method to identify obesity/overweight in children and depends on accurate weighing and measuring and making correct clinical judgments on the appropriateness of a child's pattern of growth, for most clinical, screening and surveillance purposes [30]. However, its under-utilization by healthcare providers, in particular in primary care setting, has been a point of concern [12-17, 31]. While it can be argued that the use of online BMI calculator and electronic health record and their integration to the clinical practice would enhance the use of BMI and the adherence to recommendations for screening and identification of childhood overweight and obesity [32]; some barriers such as navigation pathway needed to locate the required obesity-related form in the electronic health record, and minimal training of physicians, consistent with those encountered in other electronic health record interventions [33], remains to be the challenges associated with implementing interventions in a complex care system [34]. Furthermore, poor information and communication technology, a limited to no access to internet, defective power resource, costs of equipment supply, and low level of technical skills can all play as barriers for health care providers in developing countries where the most burden of the disease is expected [35].

The simplified overweight screening instrument utilized in this study was previously published [18] and was developed following the methodology of Kaelber and Pickett in developing their simplified screening tool to identify children and adolescents needing further evaluation of blood pressure [36]. This simplified tool consists of two gender-specific tables, through which, 
Table 2 Baseline measurement (Mean \pm SD) for 6-11 year old children enrolled in the study

\begin{tabular}{|c|c|c|c|c|c|c|c|}
\hline & $\begin{array}{l}\text { Boys } 6-8 \text { years old } \\
(n=48)\end{array}$ & $\begin{array}{l}\text { Girls } 6-8 \text { years old } \\
(n=36)\end{array}$ & $P$-value ${ }^{*}$ & $\begin{array}{l}\text { Boys } 9-11 \text { years old } \\
(n=40)\end{array}$ & $\begin{array}{l}\text { Girls } 9-11 \text { years old } \\
(n=44)\end{array}$ & $P$-value* & $\begin{array}{l}\text { Total } \\
(N=168)\end{array}$ \\
\hline Age (months) & $91.2 \pm 9.7$ & $93.4 \pm 10.2$ & 0.31 & $122.0 \pm 9.0$ & $124.0 \pm 9.5$ & 0.34 & $107.6 \pm 18.2$ \\
\hline Weight (kg) & $27.1 \pm 5.4$ & $28.2 \pm 7.1$ & 0.41 & $35.7 \pm 8.6$ & $39.4 \pm 10.0$ & 0.07 & $32.6 \pm 9.4$ \\
\hline Height (cm) & $125.4 \pm 6.1$ & $127.5 \pm 6.8$ & 0.14 & $139.6 \pm 8.0$ & $143.0 \pm 8.9$ & 0.07 & $133.8 \pm 10.7$ \\
\hline BMI $\left(\mathrm{kg} / \mathrm{m}^{2)}\right.$ & $17.1 \pm 2.5$ & $17.1 \pm 2.9$ & 0.93 & $18.1 \pm 3.3$ & $19.0 \pm 3.7$ & 0.25 & $17.8 \pm 3.2$ \\
\hline BMI z-score & $0.5 \pm 0.9$ & $0.3 \pm 1.0$ & 0.58 & $0.2 \pm 1.1$ & $0.4 \pm 1.0$ & 0.5 & $0.4 \pm 1.0$ \\
\hline
\end{tabular}

* Independent $t$ test for differences according to gender

with the use of only the child's height and weight measurements without any additional computation, overweight screening can be performed.

There has been an increasing trends in visitation patterns of children to dentists [12], with a higher frequency of annual visits as compared to medical visits $[12,37,38]$. Children's weight and height data are being routinely collected in dental offices who care for children, as part of a new patient medical history evaluation, and for calculation of safe dosages of local anesthesia for dental treatment under conscious or deep sedation. Therefore, dentists, specially pediatric dentists, can utilize dental visits to add additional screening and counseling that complements physicians' efforts in addressing overweight or obesity and to refer those with unhealthy weight status to pediatricians or family physicians for further evaluations [14, 39]. In our setting, we found the application of this tool to be very feasible: with the minimal needed equipment, we were able to gather the weight and height from 168 children and use the tool to screen for overweight with no disruption to patient flow.

Our results showed an $89 \%$ overall agreement between the WHO BMI-for-age reference tables and the simplified screening instrument utilized in this research. In particular, the positive percent agreement of $100 \%$ means that none of the unhealthy weight individuals who were reported by WHO tables were screened as healthy weight status according to the screening tables. The only difference between the two techniques is that the simplified approach identified 18 participants as unhealthy weight status, while these participants were judged as healthy based on the WHO tables. This is in particular for the cases whose weight/height values put them on the borderline of being overweight. An example is illustrated in Fig. 1b. It can be argued that this difference is not only worrying, but also, could be a benefit for early identification of children with borderline unhealthy weight status due to the higher sensitivity of the simplified screening tables.

Although the study population was limited to a convenient university-based sample, for the purpose of the study objective, our study sample has an acceptable generalizability since $64.9 \%$ of our subjects, as compared to $65.5 \%$ of Canadian children from the Canadian Health Measurement Survey [40], had healthy weight status $(P$ $=0.72$ ). Hence, based on the generalizability and validity of this simplified screening instrument, it is expected that this screening tool would remove the burden of BMI calculation and would hopefully enhance overweight triage in primary care settings as well as schoolbased and community surveillance efforts [18]. It has to be acknowledged that regardless, the healthcare professionals, specially those who care for children, would still need to have access to appropriate equipment to measure weight and height, introduce the idea of taking these measurements then undertake these measurements. At the end, health care professionals should promote active healthy living within each family unit, with focus on health rather than the actual weight numbers or physical appearance [41]. An important aspect of the clinician's responsibility that remains is related to communicating the overweight screening results to the parent in a supportive and culturally appropriate way rather than an

Table 3 Weight status comparison using the WHO's 2007 BMl-for-age tables vs. simplified overweight screening instrument

\begin{tabular}{lllll}
\hline Weight status comparison & & WHO's 2007 BMI-for-age tables & \\
\cline { 3 - 5 } & & Unhealthy $\mathrm{n}(\%)$ & Healthy $\mathrm{n}(\%)$ & Total $\mathrm{n}(\%)$ \\
\hline Simplified Screening & Unhealthy $\mathrm{n}(\%)$ & $59(35.11)(\mathrm{a})$ & $18(10.71)(\mathrm{b})$ & $77(45.83)$ \\
& Healthy $\mathrm{n}(\%)$ & $0(0)(\mathrm{c})$ & $91(54.16)(\mathrm{d})$ & \\
& Total $\mathrm{n}(\%)$ & $59(35.11)$ & $109(64.88)$ & $168(100)$ \\
\hline
\end{tabular}

This table shows the weight status comparison by using WHO's 2007 BMI-for-age tables vs. the study simplified overweight screening instrument

Overall percent agreement $=100 \% \times(a+d) /(a+b+c+d)=100 \% \times 150 / 168=89 \%$

Positive percent agreement $=100 \% \times \mathrm{a} /(\mathrm{a}+\mathrm{c})=100 \% \times 59 / 59=100 \%$

Negative percent agreement $=100 \% \times d /(b+d)=100 \% \times 91 / 109=83 \%$ 
accusatory way [42], in a manner that avoids judgment and the instillation of guilt in the parents [39].

\section{Conclusions}

This study has demonstrated the feasibility of weight, height and BMI measurement in a dental setting. It has further shown evidence that supports validity of a new simplified approach to assess children's weight status without having to compute BMI. This simplified screening can enhance overweight triage in primary care settings as well as school-based and community surveillance efforts. Dentists who collaborate with other health care professionals have the potential to address childhood overweight/obesity and should determine height, weight for their patients at least annually and refer patients with unhealthy weight status to pediatricians, family physicians or registered dieticians.

\section{Additional file}

Additional file 1: Screening weights for overweight in girls and boys. Screening weights for overweight in girls (Table S1.) and boys (Table S2.) based on age and 2007 WHO Reference height percentiles and BMI. (PDF $1276 \mathrm{~kb}$ )

\section{Abbreviations}

BMI: Body mass index; WHO: World Health Organization.

\begin{abstract}
Acknowledgement
The authors would like to gratefully acknowledge Junmin Yang for assistance with data analyses, Snezana Djuric for her clinic assistance, Adam Sgro, Santa Rabi, Sara Marandi, and Nima Laghapour-Lighvan for their help with the manuscript. This manuscript is based upon Master of Science thesis submitted by Anoushe Sekhavat to the University of Toronto in 2014 (https://tspace.library.utoronto.ca/bitstream/1807/68056/1/Sekhavat_Anoushe_201411_MSc_thesis.pdf). She expresses her special gratitude to Dr. Hashim Nainar, Faculty of Dentistry, University of Toronto as this work would have not been possible without his help.
\end{abstract}

\section{Funding}

This study was funded by Discipline of Pediatric Dentistry, Faculty of Dentistry, University of Toronto.

\section{Availability of data and materials}

More data related to this work is available from https://

tspace.library.utoronto.ca/bitstream/1807/68056/1/

Sekhavat_Anoushe_201411_MSc_thesis.pdf. De-identified raw data may be available upon request from the corresponding author.

\section{Authors' contributions}

AA, AS, and MJS conceptualized and designed the study. AS conducted the study. AA and AS performed the data analysis and interpretation. AA prepared the manuscript. AA and AS reviewed and revised the manuscript. All authors read and approved the final manuscript as submitted.

\section{Competing interests}

The authors declare no potential conflicts of interest with respect to the authorship and/or publication of this article.

\section{Consent for publication}

Not applicable.

\section{Ethics approval and consent to participate}

The research protocol and its written informed consent were approved by the Research Ethics Board of the University of Toronto (Protocol No. 28052).
Written consent to participate was given on behalf of the children (under the age of 16) by their parents/legal guardians.

\section{Author details}

${ }^{1}$ Faculty of Dentistry, University of Toronto, 710F-481 University Ave, Toronto, ON M5G 2P1, Canada. ${ }^{2}$ Department of Dentistry, Mount Sinai Hospital, Toronto, Canada. ${ }^{3}$ Institute of Health Policy, Management and Evaluation, Faculty of Medicine, University of Toronto, Toronto, Canada. ${ }^{4}$ Toronto Health Economics and Technology Assessment Collaborative, University of Toronto, Toronto, Canada.

Received: 26 April 2016 Accepted: 7 February 2017

Published online: 17 February 2017

\section{References}

1. UNICEF, WHO, World Bank. Levels and trends in child malnutrition: UNICEFWHO-World Bank joint child malnutrition estimates. UNICEF, New York; WHO, Geneva; World Bank, Washington DC: 2015.

2. World Health Organization: Childhood overweight and obesity. http://www. who.int/dietphysicalactivity/childhood/en/. Accessed 4 Nov 2016.

3. Lau DC, Douketis JD, Morrison KM, Hramiak IM, Sharma AM, Ur E. Canadian clinical practice guidelines on the management and prevention of obesity in adults and children [summary]. CMAJ 2006-2007; 176 Supple 8:1-13.

4. US Preventive Services Task Force, Barton M. Screening for obesity in children and adolescents: US Preventive Services Task Force recommendation statement. Pediatrics. 2010;125(2):361-7. doi:10.1542/peds. 2009-2037.

5. Krebs NF, Jacobson MS. Prevention of pediatric overweight and obesity. Pediatrics. 2003:112:424-30.

6. Barton M. Screening for obesity in children and adolescents: US Preventive Services Task Force recommendation statement. Pediatrics. 2010;125:361-7.

7. Barlow SE, Dietz WH. Obesity evaluation and treatment: Expert Committee recommendations. The Maternal and Child Health Bureau, Health Resources and Services Administration and the Department of Health and Human Services. Pediatrics. 1998;102:E29.

8. Mechanic D, McAlpine DD, Rosenthal M. Are patients' office visits with physicians getting shorter? N Engl J Med. 2001;344:198-204.

9. de Onis M, Onyango AW, Borghi E, Siyam A, Nishida C, Siekmann J. Development of a WHO growth reference for school-aged children and adolescents. Bull World Health Organ. 2007;85:660-7.

10. Khan LK, Sobush K, Keener D, Goodman K, Lowry A, Kakietek J, Zaro S. Recommended community strategies and measurements to prevent obesity in the United States. MMWR Recomm Rep. 2009;58:1-26.

11. Centers for Disease Control and Prevention. Overweight and Obesity. http:// www.cdc.gov/nccdphp/dnpao/division-information/index.htm. Acesssed 8 Nov 2015

12. Sesselberg TS, Klein JD, O'Connor KG, Johnson MS. Screening and counseling for childhood obesity: results from a national survey. J Am Board Fam Med. 2010;23:334-42.

13. Wethington HR, Sherry B, Polhamus B. Physician practices related to use of BMI-for-age and counseling for childhood obesity prevention: A crosssectional study. BMC Fam Pract. 2011;12:80.

14. Curran AE, Caplan DJ, Lee JY, Paynter L, Gizlice Z, Champagne C, et al. Dentists' attitudes about their role in addressing obesity in patients: a national survey. J Am Dent Assoc. 2010;141:1307-16.

15. Mabry IR, Clark SJ, Kemper A, Fraser K, Kileny S, Cabana MD. Variation in establishing a diagnosis of obesity in children. Clin Pediatr (Phila). 2005:44:221-7.

16. Daniels SR. The use of BMI in the clinical setting. Pediatrics. 2009;124 Suppl 1:35-41.

17. Braithwaite AS, Vann Jr WF, Switzer BR, Boyd KL, Lee JY. Nutritional counseling practices: how do North Carolina pediatric dentists weigh in? Pediatr Dent. 2008:30:488-95.

18. Nainar SM. Simplified screening for overweight in children using the 2007 WHO Reference. Pediatr Obes. 2012:7:e1-8.

19. Azarpazhooh A, Sekhavat A, Sigal MJ: Efficacy of Nutrition and Physical Activity Counselling for Pre-adolescent Children in a Dental Setting: A Randomized Clinical Trial. https://tspace.library.utoronto.ca/bitstream/1807/ 68056/1/Sekhavat_Anoushe_201411_MSc thesis.pdf (2014). Accessed 29 Mar 2016. 
20. Canadian Health Measures Survey: Cycle 2 - Household Questionnaire. Ottawa: Statistics Canada; 2009-2011. http://www23.statcan.gc.ca/imdb/ p2SV.pl?Function=getSurvey\&ld=62444. Accessed 29 Feb 2016.

21. School Food And Beverage Policy. Ontario: Ministry of Education; 2010. http://www.edu.gov.on.ca/eng/healthyschools/PPM150_Resource_Guide_ 2010.pdf. Accessed 8 Nov 2015.

22. Manitoba School Nutrition Handbook. Manitoba: Government of Manitoba; 2006. http://www.gov.mb.ca/healthyschools/foodinschools/documents/ handbook.pdf. Accessed 29 Feb 2016.

23. Department of Health and Human Services. Maternal and Child Health 2000 Growth Charts Training. http://depts.washington.edu/growth/index.htm. Accessed 8 Nov 2015.

24. World Health Organization. 2007 BMI-for-age. Extended tables for constructing national health cards, Z-score for boys and girls. http://www. who.int/childgrowth/standards/bmi_for_age/en/. Accessed 8 Nov 2015.

25. Sim J, Wright CC. The kappa statistic in reliability studies: use, interpretation, and sample size requirements. Phys Ther. 2005;85(3):257-68.

26. Feinstein AR, Cicchetti DV. High agreement but low kappa: I. The problems of two paradoxes. J Clin Epidemiol. 1990;43:543-9.

27. US Food and Drug administration. Statistical guidance on reporting results from studies evaluating diagnostic tests. http://www.fda.gov/ MedicalDevices/DeviceRegulationandGuidance/GuidanceDocuments/ ucm071148.htm. Accessed 29 Mar 2016.

28. Latzer Y, Stein D. A review of the psychological and familial perspectives of childhood obesity. J Eat Disord. 2013;1:7. doi:10.1186/2050-2974-1-7. eCollection 2013.

29. Ice CL, Cottrell L, Neal WA. Body mass index as a surrogate measure of cardiovascular risk factor clustering in fifth-grade children: results from the coronary artery risk detection in the Appalachian Communities Project. Int J Pediatr Obes. 2009;4:316-24.

30. Himes JH. Challenges of accurately measuring and using BMI and other indicators of obesity in children. Pediatrics. 2009;124 Suppl 1:3-22.

31. Huang JS, Donohue M, Golnari G, Fernandez S, Walker-Gallego E, Galvan K et al. Pediatricians' weight assessment and obesity management practices. BMC Pediatr. 2009;9:19.

32. Saviñon C, Taylor JS, Canty-Mitchell J, Blood-Siegfried J. Childhood obesity: Can electronic medical records customized with clinical practice guidelines improve screening and diagnosis? J Am Acad Nurse Pract. 2012;24(8):46371. doi:10.1111/j.1745-7599.2012.00735.x. Epub 2012 Apr 26

33. Miller RH, Sim I. Physicians' use of electronic medical records: barriers and solutions. Health Affair. 2004;23(2):116-26.

34. Steglitz J, Sommers M, Talen MR, Thornton LK, Spring B. Evaluation of an electronic health record-supported obesity management protocol implemented in a community health center: a cautionary note. J Am Med Inform Assoc. 2015;22(4):755-63. doi:10.1093/jamia/ocu034. Epub 2015 Feb 8.

35. Ajuwon G, Popoola S. Influence of Internet Accessibility and Demographic factors on utilization of Web-based Health Information Resources by Resident Doctors in Nigeria. Afr J Med Med Sci. 2014;43 Suppl 1:61-71.

36. Kaelber DC, Pickett F. Simple table to identify children and adolescents needing further evaluation of blood pressure. Pediatrics. 2009;123(6):e972-4. doi:10.1542/peds.2008-2680. Epub 2009 May 4.

37. Brown EJ. In: Quality AFHRA, editor. Children's dental visits and expenses, United States, 2003. Rockville: AHRQ Publication; 2006. Statistical Brief no. 117.

38. Selden TM. Compliance with well-child visit recommendations: Evidence from the Medical Expenditure Panel Survey, 2000-2002. Pediatrics. 2006;1 18: e1766-78.

39. Tseng R, Vann Jr WF, Perrin EM. Addressing childhood overweight and obesity in the dental office: rationale and practical guidelines. Pediatr Dent. 2010;32(5):417-23

40. Roberts KC, Shields M, de Groh M, Aziz A, Gilbert JA. Overweight and obesity in children and adolescents: results from the 2009 to 2011 Canadian Health Measures Survey. Health Rep. 2012;23:37-41.

41. Secker D. Promoting optimal monitoring of child growth in Canada: using the new WHO growth charts. Can J Diet Pract Res. 2010;71(1):e1-3.

42. Dietz WH, Story MT, Leviton LC. Issues and implications of screening, surveillance, and reporting of children's BMI. Pediatrics. 2009;124 Suppl 1: S98-101. doi:10.1542/peds.2008-3586M.

\section{Submit your next manuscript to BioMed Central and we will help you at every step:}

- We accept pre-submission inquiries

- Our selector tool helps you to find the most relevant journal

- We provide round the clock customer support

- Convenient online submission

- Thorough peer review

- Inclusion in PubMed and all major indexing services

- Maximum visibility for your research

Submit your manuscript at www.biomedcentral.com/submit
Biomed Central 